\title{
Analysis of icatibant for the treatment of laryngeal hereditary angioedema attacks in the FAST-3 study
}

\author{
William Yang ${ }^{1 *}$, Jacques Hébert ${ }^{2}$, Bruce Ritchie ${ }^{3}$, Jovanna Baptista ${ }^{4}$, Marc Riedl $^{5}$, William R Lumry ${ }^{6}$ \\ From Canadian Society of Allergy and Clinical Immunology Annual Scientific Meeting 2014 \\ Ottawa, ON, Canada. 23-26 October 2014
}

\section{Background}

The efficacy and safety of icatibant for the treatment of edematous hereditary angioedema (HAE) attacks was established in three Phase III trials, including the For Angioedema Subcutaneous Treatment-3 study (FAST-3; NCT00912093). Here, data from the double-blind, controlled phase and open-label extension (OLE) of FAST-3 were analyzed post-hoc to specifically evaluate icatibant for the treatment of laryngeal attacks, which can cause potentially fatal airway obstruction.

\section{Methods}

Controlled phase: adults with HAE type I/II were randomized to a single subcutaneous injection of icatibant 30 mg or placebo for their first mild-to-moderate laryngeal attack or moderate-to-very severe cutaneous/abdominal attack; severe laryngeal attacks were treated with openlabel icatibant. OLE: attacks were treated with up to three icatibant injections, at $\geq 6$-hour intervals. Three outcomes were analyzed for first icatibant-treated laryngeal attacks: 1) time to onset of symptom relief (earliest of three consecutive measurements for which there was a $50 \%$ reduction of patient-assessed 5-symptom composite $100 \mathrm{~mm}$ visual analog scale [VAS]); 2) time to almost complete symptom relief (earliest of three consecutive measurements for which all VAS symptom scores $<10 \mathrm{~mm}$ ); 3 ) patient- and investigator-assessed time to initial symptom improvement. Reinjection rates were also recorded.

\section{Results}

For first icatibant-treated laryngeal attacks in the controlled phase or OLE $(n=27)$, median $(95 \% \mathrm{CI})$ time to onset of symptom relief was 2.0 (1.5-3.5) hours, median (95\% CI) time to almost complete symptom relief was $6.0(3.0-24.3)$ hours, and median $(95 \% \mathrm{CI})$ patient- and

${ }^{1}$ Allergy \& Asthma Research Centre, Ottawa, ON, Canada

Full list of author information is available at the end of the article investigator-assessed time to initial symptom improvement was 0.7 (0.4-0.9) and 0.8 (0.5-1.1) hours, respectively. In the OLE, 41/43 (95.3\%) laryngeal attacks were treated with one icatibant injection, 2/43 (4.7\%) were treated with two injections, and none required three injections.

\section{Conclusions}

Icatibant provided symptom relief for mild-to-severe laryngeal HAE attacks in FAST-3. In the OLE, almost all laryngeal attacks were treated with one injection only.

\section{Authors' details}

${ }^{1}$ Allergy \& Asthma Research Centre, Ottawa, ON, Canada. ${ }^{2}$ Centre de Recherche Appliquée en Allergie de Québec, Québec City, QC, Canada. ${ }^{3}$ University of Alberta, Edmonton, AB, Canada. ${ }^{4}$ Shire, Lexington, MA, USA. ${ }^{5}$ University of California - San Diego, La Jolla, CA, USA. ${ }^{6}$ AARA Research Center, Dallas, TX, USA.

Published: 18 December 2014

doi:10.1186/1710-1492-10-S2-A51

Cite this article as: Yang et al:: Analysis of icatibant for the treatment of laryngeal hereditary angioedema attacks in the FAST-3 study. Allergy, Asthma and Clinical Immunology 2014 10(Suppl 2):A51.

Submit your next manuscript to BioMed Central and take full advantage of:

- Convenient online submission

- Thorough peer review

- No space constraints or color figure charges

- Immediate publication on acceptance

- Inclusion in PubMed, CAS, Scopus and Google Scholar

- Research which is freely available for redistribution 